\title{
EL ESTADO NUTRITIVO DEL LACTANTE Y LAS CONDICIONES DE VIDA DE SU GRUPO FAMTLAR
}

\author{
Por los Dres. ALBERTO DUARTE GONZALEZ. WERNER BUSTAMANTE ESPINOZA \\ y V. S. FRIEDA PUEBLA LEESON. \\ Dircción General de Protección a la Infancia y Adolescencia.
}

E1 presente trabajo representa el estudio de las condiciones de vida de las familias cuyos lactantes estuvieron inscritos y fueron atendidos regularmente durante 2 años en los Centros Materno Infantiles de la Dirección General de Protección a la Infancia y Adolescencia. en la capital.

Los mencionados lackantes fueron objeto de las atenciones médicas y sociales que en dichos Servicios se dispensan y que se han standardizado en riuestro país en la asistencia del lactante, incluyendo, fundamentalmente, las siguientes:

a) control médico periódico realizado por el pediatra:

b) suministro de leche:

c) inmunizaciones;

d) tratamiento de las enfermedades, suministro de medicamentos y hospitalización del niño en caso necesario;

e) educación sanitaria, supervigilancia de la alimentación y coltrol de los tratamientos en el domicilio, por la Enfermera Sanitaria:

d) atención social de la familia, por la Visitadora Social, que incluye: caso social individual; ayudas controladas de dinero y especies: trabajo social de grupo (clubes de costura, de economía doméstica, de confección infantil, de industrias domésticas, de enseñanza de la puericultura, etc.).

Se tomaton las fichas correspondientes a los lactantes que habían cumplido 2 años de edad y se separaron en 2 gru $^{-}$ pos: uno, correspondiendo a aquéllos cuyo diagnóstico final era de eutróficos, y otro. correspondiendo. a aquéllos cuyo diagnóstico final fué de distróficos. Se eliminaron aquellos casos en los que la asistencia al Servicio habia sido irregular, de tal manera reunidos, se tomaron al azar cincuenta fichas de cada uno de los grupos. La familia de carla uno de estos lactanies fué el objeto de nuestra investigación.

La condición de distróficos establecida en el diagnóstico final se determinó aplicando el criterio generalmente aceptado en nuestro pais, en orden a estimar como tales a aquellos lactantes que, además de evidenciar un peso y una estatura ubicados por debajo del margen mínimo correspondiente a su edad, presentaron signos de disergia, retraso de las funciones estático-dinámicas, retraso del desarrollo psicológico, gráfica ponderal tórpida, intolerancia alimenticia, etc.

Se consideró conveniente investigar hasta qué punto las características económico sociales de cada familia hạbian concutrido para determinar el estado nutritivo de los lactantes, todos los cuales recibieron regularmente la misma atencióli médico-social de parte del Servicio durante los 2 años.

La investigación se realizó por medio de una encuesta domiciliaria, que incluyó los rubros más representativos de la vida doméstica. La comparación de los resultados permitiría apreciar a cuáles de ellos podrían considetarse como factores predisponentes o determinantes de la distrofia. 
Material de trabajo.

Las poblaciones estudiadas cubren sectores geográficos sensiblemente semejantes (Barrios Matadero, Hipódromo Chile, Bascuñán Guerrero), reclutándose la clientela de estos Centros entrs las familias no afiliaclas al Seguro Socia] y con disponibilidacles económicas más o menos precarias.

\section{Resultados obtenidos.}

En forma resumida expondremos a continuación los resultados obtenidos para algunos rubros de la encuesta que hemos considerado de interés y que pueden servir de referencia para futuras investigaciones médico-sociales.

Constitución de la familia. - Los hogares legalmente constituidos son apreciablemente más numerosos entre las familias con lactantes eutróficos. $\mathrm{Te}^{-}$ remos un $91 \%$ entre estos lactantes $y$ un $78 \%$ entre los distróficos. Hay el $8,9 \%$ de solteros que mantienen unión libre en las familias con niños eutróficos, y el $22 \%$ en los distróficos. Es denıasiado conocido el hecho de que el $\mathrm{pa}^{-}$ dre soltero se siente con menos responsabilidad ante sus hijos y elude más fácilmente las obligaciones ante éstos.

Factor cultural. - El factor cultural. al cual está ligada la capacidad de organizar bien la vida familiar, reforzar los lazos afectivos, concertar los gastos, dirigir la alimentación, supervigilar los cuidados del lactante particularmente y de los familiares, tiene gran importancia. Entre los distróficos encontramos el $20 \%$ de padres analfabetos $y$ el $26 \%$ en las madres. Entre los eutróficos, el 1,8 \% de los padres son analfabetos y el $9 \%$ entre las madres. Estas cifras son muy representativas si consideramos que el analfabetismo es un índice, del nivel cultural de la familia. La madre analfabeta queda ajena a la acción de la educación impartida a base ile carteles, gráficos, folletos, etc., encon- trando por lo tanto, serias dificultades para aprender lo que debe saber para criar a su hijo.

Alcoholismo. - Hemos observado en estos grupos familiares que na bebe el $39,3 \%$ de los padres de hijos eatróficos $y$ el $26 \%$ en los distróficos. Bebedores ocasionales encontramos el $48,2 \%$ en los eutróficos y $56 \%$ en los distróficos. Bebedor habitual, 12,5\% en los eutróficos y $18 \%$ en los distróficos. Debemos considerar la existencia del vicio del alcohol en una familia como índice que mide el nivel motal con la más sensible aproximación, y, por lo tanto, como un factor adverso en la vida familiar.

Trabajo. - El 71,3\% de los padres con hijos eutróficos tienen un trabajo estable $y$ lo tienen sólo el $68 \%$ en los distróficos. El trabajo es de tipo ocasional en el $9 \%$ para los primeros y en e] $12 \%$ para los distróficos. Sabemos que la estabilidad del trabajo proporciona también una estabilidad económca, y por lo tanto, el niño de este griopo familiar está menos expuesto a una distrofia. También consideramos aquí muy importante la cesantia del padre y los que estaban fuera del hogar. ya que en ambos casos no se recibe el aporte de ellos. Nos encontramos con un $10 \%$ de los padres de los niños eutróficos, cesantes y el $12 \%$ de los distróficos. El $7 \%$ de los primeros y el $8 \%$ de los segundos estaban fuera del hogar. En ambos aspectos (cesantía y abandono) la familia de ambas categorias de niños se encuentran casi en igualdad de condiciones. En cuanto al trabajo que desempeñan las madres, no encontramos cifras que fueran. muy representativas. E1 $10 \%$ de las madres de eutróficos tienen un trabajo estable y el 7,1\% ocasional. En las madres de distróficos. encontramos el $7 \%$ y el $10 \%$, respectivamente. El número de madres que trabajan en ambos grupos, es muy reducillo para sacar conclusiones. 
Vivienda. - Creemos necesario hacer un alcance con relación a los tipos de vivienda que denominamos mejora $y$ callampa. Por mejora se entiende una construcción ligera levantada en predio ajeno con el consentimiento del propietario, quien aprovecha al mejorero para que cuide el predio. Callampa es una vivienda ligera, que junto con otras del mismo estijo, están construídas en tetrenos municipales o fiscales, constituyendo una población desprovista de los elementos más esenciales de urbanización y de salubridad.

A contjnuación expondremos los resultados obtenidos:

\begin{tabular}{lccc}
\hline & $\begin{array}{c}\text { Familias de } \\
\text { distróficos }\end{array}$ & $\begin{array}{c}\text { Familias de } \\
\text { eutróficos }\end{array}$ \\
\hline Cass & $34 \%$ & $53,5 \%$ \\
Clte & $22 \%$ & $14 \%$ \\
Conventillo & $20 \%$ & $16,1 \%$ \\
Mejora & $14 \%$ & $3,6 \%$ \\
Callampa & $10 \%$ & $1,8 \%$ \\
Personas por pieza & 6,2 & 4,5 \\
Personas por cama & 3 & 2 \\
Agua patable & $76 \%$ & $82,8 \%$ \\
Sin agua & $24 \%$ & $7,2 \%$ \\
Alcantarllado & $72 \%$ & $85,8 \%$ \\
Pozo megro & $4 \%$ & $8,8 \%$ \\
Pozo séptico & $4 \% \%$ & $1,8 \%$ \\
Sin servicio & $20 \%$ & $3,6 \%$ \\
Luz eléctrica & $64 \%$ & $85,7 \%$ \\
Velas y otros & $36 \%$ & $14,3 \%$
\end{tabular}

Con respecto al tipo de vivienda, es evidente que las familias con hijos eutróficos viven en mejores condiciones que las familias con hijos distróficos, quienes moran de preferencia en habitaciones de tipo conventillo o callampa. En resumen, según los datos recogidos, se confirma el hecho de que una mald habitación, sin salubridad ni higiene, cs un factor de primordial importancia en la génesis de la distrofia.

Entradas mensuales. - Es curioso anotar que entre las familias de los eutróficos se contaban cinco que vivian como-allegados en casa de familiares.
Ello puede explicarse debido a que en las familias de eutróficos encontramos mayor número de obreros calificados, los cuales, al verse cesantes, esperan a veces largo tiempo un trabajo que esté de acuerdo con su especialidad. En cambio. los no calificados, acostumbran a efectuar cualquiera clase de trabajo y desemprĩan el que tengan oportunidad de hacer. La mayor frecrencia de entrada mensual la teuemos entre dos mil y tres mil pesos para los distróficos y entre tres mil y cuatro mil pesos para los eutróficos.

Vestuario. - El 44,6\% de las familias de niños eutróficos cuenta con un presupuesto mensual para vestuario y el $36 \%$ en los distróficos. Igual porcentaje en las familias con eutróficos que compra ropa al contado y el $26 \%$ en los distróficos. En este últimio grupo hay una gran mayoría que viste con ropa usada regalada.

Alimentación. - Para clasificar la alimentación familiar hemos utilizado tres categorias convencionales: satisfactoria, deficiente y absolutamente deficiente. En el grupo satisfactorio incluímos aquellas familias en que la alimentación es habitualmente completa, encontrándose casi todos los requerimientos de prótidos, glúcidos, lípidos, sales y vitaminas. En el grupo deficiente se incluye aquel grupo que adolece de an déficit en albúminas, principalmente por sub consumo de leche y carne. En el último grupo no sólo reunimos aquéllos con carencia en prótidos y en otros principios alimenticios, sino que, además, es irregular, es decir, no es diaria. Es de gran importancia conocer la alimentación familiar, pues hasta los seis meses los requerimientos alimenticios del lactante pueder quedar cubiertos sea por el seno materno o por los aportes de leche del Servicio o por ambos, según sean las condiciones individuales de cada caso. En los meses siguientes la dieta del lactante es inevitablemente influída por la modalidad del grupo familiar a que per 
tenece. Si se dispone de poco tiempo pata la alimentación, lógicamente que ésta será deficiente y. escasa, repercutiendo también en el estado nutritivo del niño.

En anibos tipos de familia encontramos una sub alimentación, pero mucho más acentuada eu las familius con níños distróficos. La mayor frecuencia del presupuesto diario por persona en los distróficos fué entre los $\$ 7$ y $\$ 9$ por persona. En los eutróficos esta cifra alcanzó entre los $\$ 10$ y $\$ 15$ diarios. En aquellas familias con menos de $\$ 7$ diarios par persona no encontramos niños eutróficos.

\section{Eutróficos Distróficos}

Alimentación familiar:

$\begin{array}{llr}\text { Satisfactoria } & 25 \% & 2 \% \\ \text { Deficiente } & 37,7 \% & 30 \% \\ \text { Aldsolut. insuficiente } & 37,5 \% & 68 \%\end{array}$

En cuanto al consumo de leche encontramos sólo 24 familias en los distróf - $^{-}$ cos que consumen leche, siento esta cantidad alrededor de $\operatorname{los} 150$ y $250 \mathrm{~g}$ diarios por persona. E1 $52 \%$ de los casos no consume leche. En los eutróficos tenemos 44 familias consumiendo leche, alcanzando alrededor de $\operatorname{los} 236$ y $320 \mathrm{~g}$ a] día por persona $\mathrm{E} 1$ 19,7 \% de esta. familias no consume leche. La falta de leche puede inputarse como un factor decisivo en la aparición de la distrofia, pues se encuentra íntimamente ligado con la alimentación, es decir, con su calidad y canticlad, debiendo considerarse los consumos de leche como el índice más exacto del modo alimenticio familiar.

\section{Comentario.}

Las condiciones generales de vida de las familias con un lactante distrófico son absolutamente inferiores a aquellas que prevalecen en las familias cuyo lactante es eutrófico.

Si todos los niños fueron sometidos por igual al régimen de protección médico-social otorgado por el Servicio y si al final de la lactancia unos llegaron como eutróficos y otros como distróficios, es lícito inferir que existen factores predisponentes y determinantes de la distrofia que radican en las condiciones adversas de su vida faniliat. En nuestra investigación hexuos comprobado que hay niveles de vida bajo los cuales es imposible lograr un lactante eutrófico. El factor que cll esta circunstancia rige con decisiva influencia en la vida doméstica es el económico; los otros le siguen en importancia, san su reflejo y dependen o están intimamente ligados a él.

Este hecho implica una fuerte limitación en los resultados del trabajo médico. ya que la rehabilitación de la familia en crisis y su restitución a la nommalidad caen en absoluto fuera del radio de in. fluencia de la acción médica. Las condiciones de vida de la familia en particular y de la comunidad en general, están determiniadas, fundamentalmente. por una serie de factores de orden económico y médico social y político que prevalecen en cada país en un momento determinado.

Los Médicos, Visitadoras y Enferneras se ven enfrentados a serios problemas y dificultades crando tratan de articular una acción coordinada para luchar contra la distrofia, y ello en razón de las circunstancias señaladas. Estimamos, en consecuencia que, enfocado el nisunto desde este punto de vista, debe llegarse a la conclusión de que el esquema técnico habitualmente seguido en nuestro pais para la protección del lactante, debe ser objeto de serias rectificaciones, tomando en consideración el factor médico-social del grupo familiar, si consideramos la lucha contra la distrofia como uno de sus ubjetivos más importantes.

\section{Resumen.}

Se dan a conocer los resultados obtenidos en un estudio realizado en los Centros Preventivos Materno Infantiles dependientes de la Dirección Genetal de Protección a la Infancia y Adolescencia, donde se investigó el estado nutritivo del lactante y las condiciones de vida do su grupo familiar. 
Se analizaron dos grupos de familias, uno correspondiente a aquéllos cuyos lactantes eran eutróficos y otros en los que eran distróficos al cumplir 2 años de atención continuada en dichos Centros, comparando posteriormente las condiciones de vida de ambos grupos familiares, especialmente los factores culturales, constitución legal de la familia, alfabetismo, alcoholismo, trabajo, vivienda, alimenta ción familiar, ete.

Se comprueba que las condiciones generales de wida de las familias con un lactante distrófico son absolutamente inferiores a aquellas que prevalecen en las familias cuyo lactante es eutrófico, estableciéndose que hay factores predisponentes y determinantes en la distrofia que radican en las malas condiciones económico-sociales y sanitarias en que vive el grupo familiar y existiendo viveles de vida bajo los cuales es imposible lograr un lactante eutrófico.
Concluyen insistiendo en la recesidad de revisar los programas de protección materno-infantil, dando la importancia que merece el factor médico-social del grupo familiar en la lucha contra la distrofia.

\section{Summary.}

Two groups of families, one with a eutrophic child and the other with a dystrophic child controled in the Maternal and Child Preventive Service for a period of two years, were investigated in their economic, cultural. sanitary and social factors.

A comparison of these factors in the two groups of families revealed that the standard of living is much lower in those families with a dystrophic child.

The medical-social factor in a family must be taker into account in any program of pediatric welfare services for the influence in the onset of dystrophy. 